\title{
Comparison of the development ability of the northern root-knot nematode Meloidogyne hapla Chitwood, 1949 on selected species and varieties of Fabaceae Lindl.
}

\author{
Porównanie zdolności rozwoju guzaka północnego \\ Meloidogyne hapla Chitwood, 1949 na wybranych gatunkach \\ i odmianach roślin bobowatych Fabaceae Lindl.
}

\author{
Renata Dobosz*, Roman Krawczyk
}

\begin{abstract}
Summary
Legumes of the genera Vicia, Pisum, Lupinus, Trifolium, Medicago as well as Onobrychis viciifolia, Lotus corniculatus, Ornithopus sativus, Galega orientalis and Lens culinaris were cultivated in pots filled with soil naturally infected with Meloidogyne hapla, under controlled conditions in a glasshouse. Root galls and adult females with egg masses were observed in root systems of all plant species and cultivars included in the experiment. The most numerous occurrence of root galls was recorded on root tissues of Vicia faba, Pisum sativum, Lupinus luteus (cv. Parys) and Trifolium pratense (cv. Krynia) while adult females with egg masses on roots of Trifolium incarnatum, P. sativum (cv. Hubal), Lupinus albus and both cultivars of Medicago sativa. Approximately from 5 to 57 of eggs and juvenile stages were counted in a single mass.
\end{abstract}

Key words: Meloidogyne hapla; Fabaceae; root galls; egg masses

\section{Streszczenie}

Rośliny bobowate z rodzaju Vicia, Pisum, Lupinus, Trifolium, Medicago oraz Onobrychis viciifolia, Lotus corniculatus, Ornithopus sativus, Galega orientalis i Lens culinaris uprawiano w wazonach z glebą naturalnie zainfekowaną guzakiem północnym, w kontrolowanych warunkach w szklarni. Na korzeniach wszystkich badanych gatunków i odmian roślin obserwowano wyrośla oraz samice ze złożami jajowymi. Wyrośla wystąpiły najliczniej na korzeniach Vicia faba, Pisum sativum, Lupinus luteus (odmiana Parys) oraz Trifolium pratense (odmiana Krynia), a samice ze złożami jajowymi na korzeniach Trifolium incarnatum, Pisum sativum (odmiana Hubal), Lupinus albus oraz obu odmianach Medicago sativa. Zliczono średnio od 5 do 57 sztuk jaj i osobników młodocianych przypadających na pojedyncze złoże.

Słowa kluczowe: Meloidogyne hapla; Fabaceae; wyrośla korzeniowe; złoża jajowe

\footnotetext{
Instytut Ochrony Roślin - Państwowy Instytut Badawczy

Władysława Węgorka 20, 60-318 Poznań

*corresponding author: r.dobosz@iorpib.poznan.p
} 


\section{Wstęp / Introduction}

Guzaki Meloidogyne Göldi, 1892 są, oprócz nicieni tworzących cysty i korzeniaków, najważniejszą grupą szkodników roślin uprawnych, zarówno w regionach klimatu umiarkowanego, jak i subtropikalnego oraz tropikalnego (Evans i wsp. 1993; Luc i wsp. 2005). Nicienie z rodzaju Meloidogyne są obligatoryjnymi pasożytami roślin wyższych. Większa część cyklu rozwojowego tych zwierząt odbywa się wewnątrz korzeni żywicieli.

W rozwoju osobniczym guzaków występują: jajo, cztery stadia młodociane oraz samice i samce. Rośliny zasiedlane są przez osobniki młodociane drugiego stadium (tzw. larwy inwazyjne), które wnikają do korzeni roślin, gdzie przechodzą kolejne etapy cyklu. Formy żeńskie pozostają osiadłe, a powiększając rozmiary ciała przyjmują kulisty kształt. Dojrzałe płciowo, robakowate samce opuszczają tkanki korzeni w celu poszukiwania samic. Osobniki żeńskie, po zapłodnieniu składają jaja do przyczepionych do ich ciał worków jajowych, w tzw. złożach jajowych. W miejscach rozwoju nicieni, w efekcie zmian anatomiczno-fizjologicznych zachodzących w tkankach korzeni, powstają charakterystyczne zgrubienia, zwane potocznie wyroślami. Wskazują one bezpośrednio na obecność Meloidogyne, a ich wielkość i kształt na wystąpienie konkretnego gatunku lub grupy gatunków (Dobosz i wsp. 2008).

Guzaki, jak guzak arachidowy Meloidogyne arenaria (Neal, 1889), guzak południowy Meloidogyne icognita (Kofoid i White, 1919) oraz guzak amerykański Meloidogyne chitwoodi Golden, O’Bannon, Santos i Finley, 1980 znane są z wywoływania poważnych strat w uprawach. Guzak arachidowy, guzak południowy oraz guzak amerykański rozwijają się na wielu roślinach jedno- i dwuliściennych, także z rodziny bobowatych Fabaceae (Griffin i wsp. 1986; Wofford i wsp. 1989; Griffin i Rumbaugh 1996; Schmidt i Bellé 2016). W Polsce najważniejszym pasożytującym nicieniem $\mathrm{z}$ rodzaju Meloidogyne jest guzak północny Meloidogyne hapla Chitwood, 1949. Nicień ten jest ważnym szkodnikiem upraw wielu gatunków roślin, takich jak np. sałata, ziemniak, marchew, a także truskawek, róż, czy w szkółkach drzew owocowych (Olthof i Potter 1972; Brzeski 1974; Viaene i Abawi 1996). Wśród licznych roślin żywicielskich tego szkodnika są też rośliny z rodzaju Phaseolus L. i Lathyrus L. oraz gatunki, takie jak: lucerna siewna Medicago sativa L., koniczyna łąkowa Trifolium pratense L., koniczyna biała Trifolium repens L., koniczyna białoróżowa Trifolium hybridum L., esparceta siewna Onobrychis vicifolia Scop., komonica zwyczajna Lotus corniculatus L. (Santo i Ponti 1985; Griffin i wsp. 1986; Wofford i wsp. 1989; Griffin i Rumbaugh 1996).

Rośliny bobowate mają szerokie zastosowanie. Są cennym źródłem białka w diecie człowieka, a w rolnictwie są wykorzystywane do produkcji wysokobiałkowych pasz treściwych, zielonek, nawozów zielonych i poplonów. Ze względu na swoje właściwości chemiczne Fabaceae wzbudziły również zainteresowanie specjalistów $\mathrm{z}$ zakresu weterynarii i medycyny poszukujących nowych rozwiązań $\mathrm{w}$ walce $\mathrm{z}$ chorobami nowotworowymi (Rafiqa i wsp.
2013; Karakas i wsp. 2016), czy pasożytami (Molan i wsp. 2000).

Wiadomo, że guzak północny rozwija się na korzeniach kilku gatunków roślin bobowatych. Wyniki te pozwalają przypuszczać, że nicień ten może zasiedlać także inne ich gatunki i odmiany.

Celem pracy była ocena oraz porównanie zdolności rozwoju $M$. hapla na wybranych gatunkach i odmianach roślin reprezentujących rodzinę Fabaceae.

\section{Materiały i metody / Materials and methods}

Doświadczenie wykonano $\mathrm{w}$ kontrolowanych warunkach temperatury $\left(20^{\circ} \mathrm{C}\right)$ i długości dnia i nocy $(16 \mathrm{~h} / 8 \mathrm{~h})$, w kabinie fitotronu. Wazony o pojemności 2 litrów napełniono glebą naturalnie porażoną guzakiem północnym (zagęszczenie $100 \mathrm{~J} 2 / 200 \mathrm{~cm}^{3}$ ), pochodzącą $\mathrm{z}$ pola $\mathrm{z}$ uprawą marchwi (Daucus carota L.). Przed wykorzystaniem gleby do doświadczenia w glebie tej uprawiano pomidora (Lycopersicon esculentum L.). W glebie umieszczono skiełkowane wcześniej nasiona 27 badanych odmian z 17 gatunków roślin bobowatych oraz nasiona pomidora pełniącego W doświadczeniu rolę kontroli. W przypadku bobiku (Vicia faba L.), łubinu wąskolistnego (Lupinus angustifolius L.) i łubinu żółtego (Lupinus luteus L.), do doświadczenia wybrano odmiany o wysokiej i niskiej zawartości odpowiednio tanin czy alkaloidów (http://www. coboru.pl/DR/charaktodmiany.aspx). W przypadku grochu (Pisum sativum L.) wytypowano odmianę pastewną Hubal i odmianę zwyczajną Lasso. Dla każdej odmiany wykonano sześć powtórzeń, po 5 roślin w każdym. Po ośmiu tygodniach rośliny usunięto, a ich systemy korzeniowe oczyszczono z przylegającej gleby. W celu wybarwienia samic guzaka w tkankach, korzenie gotowano w roztworze kwaśnej fuksyny w laktoglicerolu (Hooper 1986). Wyrośla oraz liczbę jaj w złożach jajowych zliczono za pomocą mikroskopu stereoskopowego. Stadium rozwoju poszczególnych osobników guzaka w tkankach określono używając mikroskopu biologicznego Axioskop 2+ Carl Zeiss.

Wyniki poddano analizie wariancji ANOVA, a istotność różnic między średnimi oceniono testem Fishera na poziomie $\mathrm{p} \leq 0,05$.

\section{Wyniki i dyskusja / Results and discussion}

Wyrośla wskazujące na obecność guzaka wystąpiły na odmianach gatunków roślin znanych jako żywiciele guzaka północnego, jak i na tych gatunkach roślin, których status nie został dotąd określony, tj. łubin biały (Lupinus albus L.), łubin wąskolistny, łubin żółty, lucerna mieszańcowa (Medicago $\times$ varia T. Martyn), koniczyna aleksandryjska (Trifolium alexandrinum L.), koniczyna skręcona (Trifolium resupinatum L. var. majus), koniczyna inkarnatka (Trifolium incarnatum L.) oraz seradela siewna (Ornithopus sativus L.), soczewica jadalna (Lens culinaris Medik.) i rutwica wschodnia (Galega orientalis Lam.). W praktyce rolniczej uzupełnienie wiedzy w tym zakresie ma duże znaczenie. Rośliny bobowate są doskonałym 
Tabela 1. Ocena zdolności rozwoju guzaka północnego - Meloidogyne hapla Chitwood, 1949 na wybranych gatunkach i odmianach roślin bobowatych Fabaceae

Table 1. Evaluation of development ability of the northern root-knot nematode - Meloidogyne hapla Chitwood, 1949 on selected species and varieties of Fabaceae

\begin{tabular}{|c|c|c|c|c|}
\hline $\begin{array}{c}\text { Gatunek rośliny } \\
\text { Species of plant } \\
\text { n }=30\end{array}$ & $\begin{array}{l}\text { Odmiana } \\
\text { Cultivar }\end{array}$ & $\begin{array}{c}\text { Liczba wyrośli } \\
\text { przypadająca } \\
\text { na system korzeniowy } \\
\text { rośliny } \\
\text { Number of galls } \\
\text { per plant } \\
\text { root system }\end{array}$ & \begin{tabular}{|c|}
$\%$ samic ze złożami \\
jajowymi w ogólnej \\
liczbie osobników/na \\
system korzeniowy \\
Percent of females \\
with egg masses \\
in a total number \\
of specimens per root \\
system
\end{tabular} & $\begin{array}{c}\text { Średnia liczba } \\
\text { jaj i J2 w złożu } \\
\text { Mean number } \\
\text { of eggs and J2 } \\
\text { per egg mass }\end{array}$ \\
\hline $\begin{array}{l}\text { Pomidor - Tomato } \\
\text { Lycopersicon esculentum L. }\end{array}$ & Betalux & $86,2 \mathrm{ab}$ & 68,8 bcdefg & 32,4 bcdefg \\
\hline \multirow{2}{*}{$\begin{array}{l}\text { Bobik - Broad bean } \\
\text { Vicia faba L. }\end{array}$} & Olga & 56,5 de & 54,6 hgi & 33,0 bcdef \\
\hline & Optimal & 98,3 a & 52,7 ghi & 30,7 bcdefg \\
\hline \multirow{2}{*}{$\begin{array}{l}\text { Groch - Pea } \\
\text { Pisum sativum L. }\end{array}$} & Lasso & 73,5 bc & 68,7 cdefg & 31,5 bcdefg \\
\hline & Hubal & $66,0 \mathrm{~cd}$ & 91,7 a & 29,3 bcdefg \\
\hline \multirow{2}{*}{$\begin{array}{l}\text { Lubin wąskolistny - Narrow-leaved lupine } \\
\text { Lupinus angustifolius L. }\end{array}$} & Karo & $35,0 \mathrm{fg}$ & 79,6 abcdef & 57,3 a \\
\hline & Zeus & $27,2 \mathrm{gh}$ & 58,2 ghi & 20,0 efghijk \\
\hline \multirow{2}{*}{$\begin{array}{l}\text { Łubin żółty - Yellow lupine } \\
\text { Lupinus luteus L. }\end{array}$} & Parys & $63,3 \mathrm{~cd}$ & 89,5 abc & 18,3 ghijkl \\
\hline & Lord & 4,83 jk & 65,0 defghi & 25,8 bcdefgh \\
\hline $\begin{array}{l}\text { Lubin biały - White lupine } \\
\text { Lupinus albus L. }\end{array}$ & Boros & 46,7 ef & 94,3 a & 35,3 bcd \\
\hline $\begin{array}{l}\text { Koniczyna czerwona - Red clover } \\
\text { Trifolium pratense L. }\end{array}$ & $\begin{array}{c}\text { Nike } \\
\text { Altaswede } \\
\text { Krynia }\end{array}$ & $\begin{array}{l}20,5 \text { hi } \\
35,5 \text { gf } \\
95,5 \text { a }\end{array}$ & $\begin{array}{l}90,0 \mathrm{ab} \\
87,3 \mathrm{abc} \\
27,5 \mathrm{jk}\end{array}$ & $\begin{array}{l}37,3 \text { b } \\
36,2 \text { bc } \\
34,2 \text { bcde }\end{array}$ \\
\hline $\begin{array}{l}\text { Koniczyna biała - White clover } \\
\text { Trifolium repens L. }\end{array}$ & $\begin{array}{c}\text { Haifa } \\
\text { RD } 80 \\
\text { Grasslands Huia }\end{array}$ & $\begin{array}{c}11,0 \mathrm{ijk} \\
2,67 \mathrm{jk} \\
1,67 \mathrm{k}\end{array}$ & $\begin{array}{l}58,8 \text { fghi } \\
65,2 \text { defgh } \\
89,0 \text { abc }\end{array}$ & $\begin{array}{l}12,8 \text { ijkl } \\
14,8 \text { hijkl } \\
13,7 \text { ijkl }\end{array}$ \\
\hline $\begin{array}{l}\text { Koniczyna aleksandryjska - Berseem } \\
\text { Trifolium alexandrinum L. }\end{array}$ & Tigri & 10,3 ijk & 85,8 abcd & 26,8 bcdefgh \\
\hline $\begin{array}{l}\text { Koniczyna białoróżowa - Alsike clover } \\
\text { Trifolium hybridum L. }\end{array}$ & Aurora & 15,5 hij & 63,8 efghi & 24,3 bcdefgh \\
\hline $\begin{array}{l}\text { Koniczyna skręcona - Persian clover } \\
\text { Trifolium resupinatum L. }\end{array}$ & Gorsby & $10,0 \mathrm{ijk}$ & 69,8 bcdefg & 29,2 bcdefgh \\
\hline $\begin{array}{l}\text { Koniczyna krwistoczerwona - Crimson clover } \\
\text { Trifolium incarnatum L. }\end{array}$ & Opolska & $2,8 \mathrm{jk}$ & 90,8 a & 13,2 ijkl \\
\hline \multirow{2}{*}{$\begin{array}{l}\text { Lucerna siewna - Alfalfa } \\
\text { Medicago sativa L. }\end{array}$} & Bluemoon & 7,8 ijk & 100,0 a & 21,7 defghij \\
\hline & Eugenia & $2,7 \mathrm{jk}$ & 100,0 a & 29,3 bcdefg \\
\hline $\begin{array}{l}\text { Lucerna pośrednia }- \text { Variegated alfalfa } \\
\text { Medicago } \times \text { varia } \mathrm{T} \text {. Martyn }\end{array}$ & Radius & $5,7 \mathrm{jk}$ & 80,7 abcde & 22,3 cdefghi \\
\hline $\begin{array}{l}\text { Esparceta siewna - Sainfoin } \\
\text { Onobrychis viciifolia Scop. }\end{array}$ & Taja & $4,0 \mathrm{jk}$ & 45,3 hij & 39,5 bcdefg \\
\hline $\begin{array}{l}\text { Komonica zwyczajna - Birdsfoot trefoil } \\
\text { Lotus corniculatus L. }\end{array}$ & Skrzeszowicka & $11,8 \mathrm{ijk}$ & $0,67 \mathrm{l}$ & 5,31 \\
\hline $\begin{array}{l}\text { Seradela pastewna - Serradella } \\
\text { Ornithopus sativus L. }\end{array}$ & Emena & $9,3 \mathrm{ijk}$ & $17,7 \mathrm{kl}$ & $6,7 \mathrm{kl}$ \\
\hline $\begin{array}{l}\text { Rutwica wschodnia - Oriental goat's rue } \\
\text { Galega orientalis Lam. }\end{array}$ & Risa & 12,3 ijk & $25,7 \mathrm{jk}$ & 19,3 fghijkl \\
\hline $\begin{array}{l}\text { Soczewica jadalna - Lentil } \\
\text { Lens culinaris Medik. }\end{array}$ & - & $2,3 \mathrm{k}$ & $44,2 \mathrm{ij}$ & $8,7 \mathrm{jkl}$ \\
\hline
\end{tabular}

Średnie oznaczone tą samą literą nie różnią się istotnie statystycznie $(\mathrm{p} \leq 0,05)$

Means followed by the same letter are not statistically different $(\mathrm{p} \leq 0.05)$ 
przedplonem dla pozostałych roślin uprawnych, gdyż korzystnie wpływają na żyzność gleby i wzrost zawartości azotu w glebie $\mathrm{w}$ efekcie symbiozy $\mathrm{z}$ bakteriami rizobiowymi w następstwie procesu biologicznej redukcji azotu atmosferycznego. Powierzchnia uprawy roślin bobowatych grubonasiennych w latach 2005-2015 wzrosła prawie czterokrotnie i w 2015 roku były one uprawiane na powierzchni 407 tys. ha (GUS 2016). W tej grupie roślin największy udział w strukturze ich zasiewów zajmuje łubin. Natomiast powierzchnia uprawy roślin bobowatych drobnonasiennych, jak np. koniczyna i lucerna w ostatnim dziesięcioleciu nie ulegała większym wahaniom i w 2015 roku uprawiano je na powierzchni 93 tys. ha (GUS 2016).

Zaobserwowano zróżnicowanie liczby wyrośli na korzeniach między badanymi gatunkami oraz odmianami roślin $\left(\mathrm{F}_{27,139}=43,98 ; \mathrm{p}<0,0001\right)$ (tab. 1). Liczba wyrośli, którą obserwowano na korzeniach grochu odmiany Lasso, koniczyny czerwonej odmiany Krynia oraz bobiku odmiany Optimal nie różniła się od liczby wyrośli na korzeniach rośliny wzorcowej (pomidor). Wyrośla występujące na korzeniach pozostałych testowanych gatunków i odmian były mniej liczne niż te obserwowane na korzeniach rośliny kontrolnej. Wśród nich wyróżniały się gatunki i odmiany grubonasienne grochu (Hubal), bobiku (Olga), badane odmiany łubinu żółtego, wąskolistnego i białego - jako rośliny żywicielskie niewiele gorsze od rośliny wzorcowej.

Różnice w liczbie wyrośli wywołanych zasiedleniem przez guzaka północnego zanotowano między gatunkami i odmianami koniczyny. Wyrośla guzaka północnego obserwowano najliczniej na korzeniach koniczyny czerwonej odmiany Krynia, natomiast najsłabiej porażone były korzenie koniczyny białej odmiany Grasslands Huia, na które przypadły średnio tylko dwa wyrośla. Porównanie obserwacji własnych z wynikami Griffina i Rumbaugha (1996) oraz Mercera i Millera (1997) wskazują na zróżnicowanie podatności odmian koniczyny czerwonej oraz koniczyny białej na porażenie M. hapla. Wyniki te sugerują też możliwość występowania zróżnicowania zdolności porażenia odmian obu gatunków roślin wśród populacji guzaka północnego. Populacja $M$. hapla rozwinęła się znacznie słabiej na korzeniach koniczyny aleksandryjskej, szwedzkiej, skręconej oraz inkarnatki. Natomiast rośliny lucerny, rutwicy wschodniej, komonicy zwyczajnej, seradeli siewnej i esparcety siewnej charakterryzowało najniższe porażenie guzakiem, na których obserwowano odpowiednio od 12 do 4 wyrośli przypadających średnio na system korzeniowy.

Na korzeniach wszystkich uwzględnionych w doświadczeniu gatunków i odmian roślin wystąpiły samice z workami jajowymi zawierającymi jaja i osobniki młodociane stadium J2. Zanotowano istotne różnice pod względem procentowego udziału tych samic w ogólnej liczbie osobników znajdowanych w tkankach korzeni. W porównaniu $\mathrm{z}$ rośliną kontrolną, udział procentowy samic z workami jajowymi był istotnie wyższy w korzeniach koniczyny inkarnatki, grochu odmiany Hubal, łubinu białego oraz obu odmian lucerny siewnej. Równie licznie, jak w korzeniach pomidora samice $\mathrm{z}$ workami jajowymi wystąpiły w korzeniach bobiku, koniczyny aleksandryjskiej, koniczyny białej, koniczyny białoróżowej, koniczyny łąkowej w odmianach Altaswede i Nike, lucerny mieszańcowej i grochu odmiany Lasso oraz badanych odmian łubinu wąskolistnego i łubinu żółtego. Wartości istotnie niższe niż w kontroli zanotowano dla esparcety siewnej, komonicy zwyczajnej, seradeli pastewnej, rutwicy wschodniej, soczewicy oraz koniczyny łąkowej Krynia.

Liczebność jaj i osobników młodocianych J2 wewnątrz worków jajowych różniła się między gatunkami i odmianami badanych roślin. Zliczono średnio od 5 do 57 sztuk przypadających na pojedyncze złoże. Jaja i formy J2 wystąpiły liczniej niż na korzeniach rośliny-kontroli jedynie w systemach korzeniowych łubinu wąskolistnego Karo, natomiast istotnie mniej licznie w korzeniach koniczyny białej, koniczyny inkarnatki, komonicy zwyczajnej, seradeli pastewnej i soczewicy.

Przedstawione wyżej wyniki wskazały, że guzak północny chętnie zasiedla korzenie roślin bobowatych, gdzie przechodzi pełen cykl rozwojowy. Wystapienie jaj oraz inwazyjnych form młodocianych w złożach jajowych wskazuje, że rośliny bobowate dają możliwość wzrostu liczebności populacji tego nicienia oraz związanego z tym potencjalnego zagrożenia dla kolejnych upraw.

\section{Wnioski / Conclusions}

1. Istnieje zróżnicowanie porażenia gatunków i odmian roślin bobowatych przez guzaka północnego.

2. Uzyskane wyniki dają podstawę do kontynuacji prac nad występowaniem guzaka północnego na roślinach bobowatych Fabaceae w zakresie modyfikacji zagęszczenia populacji nicienia w glebie.

\section{Podziękowanie / Acknowledgements}

Autorzy dziękują Panu dr Stanisławowi Ignaczakowi z Uniwersytetu Technologiczno-Przyrodniczego w Bydgoszczy za udostępnienie nasion rutwicy wschodniej (Galega orientalis).

\section{Literatura / References}

Brzeski M.W. 1974. The reaction of carrot cultivars to Meloidogyne hapla Chitw, infestation. Zeszyty Problemowe Postępów Nauk Rolniczych 154: 173-189.

Dobosz R., Obrępalska-Stęplowska A., Nowaczyk K., Kornobis S. 2008. Diagnostyka nicieni - pasożytów roślin objętych regulacjami prawnymi. Instrukcja rozpoznawania gatunków z rodzaju Meloidogyne. Instytut Ochrony Roślin - Państwowy Instytut Badawczy, Poznań, 13 ss.

Evans K., Trudgill D., Webster J.M. 1993. Plant Parasitic Nematodes in Temperate Agriculture. CABI Publishing, Wallingford, UK, $656 \mathrm{pp}$. 
Griffin G.D., Inserra R.N., Vovlas N., Sisson D.V. 1986. Differential reaction of alfalfa cultivars to Meloidogyne hapla and M. chitwoodi populations. Journal of Nematology 18 (3): 347-352.

Griffin G.D., Rumbaugh M.D. 1996. Host suitability of twelve Leguminosae species to populations of Meloidogyne hapla and M. chitwoodi. Journal of Nematology 28 (3): 400-405.

GUS 2016. Rocznik statystyczny Rzeczypospolitej Polskiej. Główny Urząd Statystyczny, 911 ss.

Hooper D.J. 1986. Handling, fixing, staining and mounting. p. 59-80. In: ”Laboratory Methods for Work with Plant and Soil Nematodes” (J.F. Southey, ed.). Her Mayestry’s Stationery Office, London, 202 pp.

http://www.coboru.pl/DR/charaktodmiany.aspx

Luc M., Sikora R.D., Bridge J. 2005. Plant Parasitic Nematodes in Subtropical and Tropical Agriculture. CABI Publishing, Wallingford, UK, 871 pp.

Karakas F.P., Turker A.U., Karakas A., Mshvildadze V. 2016. Cytotoxic, anti-inflammatory and antioxidant activities of four different extracts of Galega officinalis L (Goat's rue). Tropical Journal of Pharmaceutical Research 15 (4): 751-757.

Mercer C.F., Miller K.J. 1997. Evaluation of 15 Trifolium spp. and Medicago sativa as hosts of four Meloidogyne spp. found in New Zealand. Journal of Nematology 29 (4): 673-676.

Molan A.L., Waghorn G.C., Min B.R., McNabb W.C. 2000. The effect of condensed tannins from seven herbages on Trichostrongylus colubriformis larval migration in vitro. Folia Parasitologica 47 (1): 39-44.

Olthof T.H., Potter J.W. 1972. Relationship between population densities of Meloidogyne hapla and crop losses in summer maturing vegetables in Ontario. Phytopathology 62: 981-986.

Rafiqa S., Majeedb R., sif Khurshid Qazib A., Ahmad Ganaia B., Wania I., Rakhshandaa S., Qurishib Y., Sharmab P.R., Hamidb A., Masooda A., Hamida R. 2013. Isolation and antiproliferative activity of Lotus corniculatus lectin towards human tumour cell lines. Phytomedicine 21 (1): 30-38.

Santo G.S., Ponti R.P. 1985. Host suitability and reaction of bean and pea cultivars to Meloidogyne chitwoodi and M. hapla. Journal of Nematology 17 (1): 77-79.

Schmitt J., Bellé C. 2016. Reaction of soybean cultivars to Meloidogyne javanica and M. incognita. Nematropica 46: 76-80.

Viaene N.M., Abawi G.S. 1996. Damage threshold of Meloidogyne hapla to lettuce in organic soil. Journal of Nematology 28 (4): 537-545.

Wofford D.S., Gray F.A., Eckert J.W. 1989. Pathogenicity of two populations of Meloidogyne hapla Chitwood on alfalfa and sainfoin. Journal of Nematology 21 (1): 87-91. 